\title{
Algunas reflexiones sobre la distancia entre "hablar química" y "comprender química"
}

\author{
Some reflections on the distance between \\ "talking chemistry" and "understanding chemistry"
}

\author{
Lydia Raquel Galagovsky ${ }^{1}$. Diana Bekerman ${ }^{2}$. \\ María Angélica Di Giacomo ${ }^{1,2}$. Salvador $\mathrm{Ali}^{2}$
}

\begin{abstract}
Resumen: Una clase de química puede ser considerada como un espacio de comunicación entre el docente experto y los estudiantes novatos, donde los lenguajes utilizados son la interfase explícita y observable del intercambio comunicativo. En el presente trabajo se muestra con dos ejemplos cómo la diversidad de lenguajes químicos en lugar de favorecer la comprensión de los estudiantes, puede actuar como fuente de obstáculos que dificultan la comunicación en el aula. Así mismo, se analizará con otros dos ejemplos cómo el discurso con el que se enseña la disciplina también es potencial generador de errores en los estudiantes, cuando ellos construyen sus modelos mentales idiosincrásicos a partir de un discurso recortado y simplificado, desde las mejores intenciones de realizar buenas transposiciones didácticas. Se plantea que un enfoque de análisis de la situación de aula como un encuentro comunicativo entre experto y novato conduce a una necesaria diferenciación entre "hablar química" y "comprender química".
\end{abstract}

Palabras clave: Enseñanza de química. Comunicación. Discurso. Didáctica. Aprendizaje.

\begin{abstract}
A class of chemistry can be considered as a forum for communication between the expert teacher and novice students, where the languages used are explicit and observable interface of a communicative exchange. In this paper we show, with two examples, how the diversity of chemical languages, instead of promoting student understanding, it can act as a source of barriers to communication in the classroom. Also, will be discussed in two examples how the speech with which the discipline is taught is also generating potential errors in students when they build their idiosyncratic mental models from a cut and simplified speech from the best intentions of make good didactic transpositions. It is argued that an approach to analysis of the situation in the classroom as a communicative encounter between expert and novice leads to a necessary distinction between "talking chemistry" and "understanding chemistry."
\end{abstract}

Keywords: Chemistry Teaching. Communication. Speech. Teaching. Learning.

\footnotetext{
${ }^{1}$ Centro de Formación e Investigación en Enseñanza de las Ciencias (CEFIEC), Facultad de Ciencias Exactas y Naturales, Universidad de Buenos Aires (UBA), Ciudad Universitaria, Pabellón 2, Av. Intendente Güiraldes, s/n, 1428, Ciudad Autónoma de Buenos Aires, Argentina. E-mail: <lydia.galagovsky@gmail.com>

${ }^{2}$ Cátedra de Química, Departamento de Ciencias Naturales, Ciclo Básico Común, Universidad de Buenos Aires (UBA), Buenos Aires, Argentina.
} 


\section{Introducción}

Una clase de ciencias es un espacio de comunicación entre el docente, experto en temáticas, y los estudiantes, donde los lenguajes utilizados son la interfase explícita y observable del intercambio comunicativo.

Una idea fuerte en didáctica de las ciencias naturales está centrada en la problemática de "hablar ciencias" (LEMKE, 1997). ¿Qué significa "hablar química" en el contexto de las clases de química? En investigaciones previas (GALAGOVSKY; BEKERMAN, 2009) hemos encontrado que "hablar química" puede llegar a ser un eufemismo cuando se da por sentado que docentes y estudiantes comparten la comprensión de aquello sobre lo que se habla. Los profesores de química debemos estar alerta sobre la complejidad y la distancia entre "hablar química" y "comprender química".

En el presente trabajo se muestran dos aspectos de potencial incomunicación entre docentes y estudiantes: por un lado, cómo la diversidad de lenguajes en lugar de favorecer la comprensión de los estudiantes, puede actuar como fuente de obstáculos que dificultan la comunicación en el aula. Por otro lado, cómo discursos científicos simplificados generan en los estudiantes modelos mentales que no se corresponden con los esperados por los expertos.

\section{El "hablar química"}

Diversos lenguajes se utilizan para comunicar el discurso de la química: lenguaje verbal en explicaciones y textos; lenguaje gráfico, tanto de nivel macroscópico como nivel atómico-molecular en dibujos y esquemas; lenguajes matemáticos en ecuaciones; lenguaje de fórmulas químicas en ecuaciones químicas, entre otros. Los docentes - y los textos- utilizan una multiplicidad simultánea de estos lenguajes con el fin de representar más cabalmente la complejidad de los conceptos teóricos abstractos (GALAGOVSKY, 2008; GALAGOVSKY; BEKERMAN, 2009) involucrados en sus definiciones, explicaciones, clasificaciones y subclasificaciones. Taber (2002) ejemplifica esta cuestión frecuentemente encontrada en el discurso de la química con el caso del concepto de "isomería". Este autor ha investigado al respecto y revela que al enseñarse el concepto desde la isomería estructural - el caso más frecuente - los estudiantes suelen reducir y "cerrar” el contexto a esta única significación, ocasionándoles problemas de aprendizaje subsiguientes cuando tienen que comprender diferentes subclases como isomería estructural, funcional y óptica.

Más allá del uso de diversos lenguajes para describir los entes abstractos y sus propiedades, las explicaciones químicas provienen de modelos que permiten interpretar hechos macroscópicos a partir de modelar funcionamientos de nivel atómico o molecular. Numerosas investigaciones dan cuenta de las dificultades de aprendizaje de la química por los estudiantes novatos (BARKER 2000; BEN-ZVI; GAI, 1994; CARMICHAEL et al. 1990; GILBERT; TREAGUST, 2009; JOHNSTONE, 1991, 2000, 2010; TABER, 2001, 2002, 2009), y, particularmente Carr (1984) argumentó que muchos de esos problemas pueden catalogarse como de "confusión de modelos". 
Es decir, "hablar química" es hablar desde modelos científicos; pero - debemos aceptar - frecuentemente la propia disciplina cuenta con varios modelos para un mismo tópico; por ejemplo, varios modelos de ácido (DE VOS; BULTE; PILOT, 2003), o de oxidación, o de modelo atómico, etc. (GROSSLIGHT et al., 1991; HARRISON; TREAGUST, 2000). Esta situación se haría más dramática para el aprendizaje de química cuando los estudiantes novatos poco reconocen de la función y el alcance del concepto de "modelos en ciencias" y cuando los propios docentes no han reflexionado sobre el tema. (GALAGOVSKY, 2011).

Si bien una revisión exhaustiva sobre las investigaciones acerca de la complejidad del uso de modelos en química queda fuera del alcance de este trabajo, analizar parte de esa complejidad desde la interacción comunicativa entre docentes y estudiantes, permitirá interpretar ejemplos de "errores conceptuales" en estudiantes con buenas calificaciones.

\section{El "comprender química"}

Comprender química supone que docentes y estudiantes llegan a compartir los significados científicos del discurso químico. Sin embargo, sendos sujetos de la comunicación tenemos grandes diferencias en nuestras respectivas competencias cognoscitivas sobre la disciplina en cuestión, por lo tanto, puede inferirse que presentar información a los estudiantes no será sinónimo de que ellos la comprendan con las significaciones que los docentes esperamos. ¿Cómo indagamos las significaciones que construyen los estudiantes a partir de nuestro discurso docente? Muy frecuentemente, los estudiantes responden bien a las preguntas con las que se los evalúa cuando éstas son meras ejercitaciones de lo enseñado; pero se revelan obstáculos de aprendizaje cuando se los indaga mediante otros instrumentos. (BEKERMAN, 2007; TALANQUER, 2006, 2010).

El estudiante que quiere aprender la disciplina química debe llegar a conocer significados, convenciones, normas, acuerdos entre expertos sobre cuáles palabras, signos, códigos, gráficos y/o formatos sintácticos son aceptables - o no -, dentro de cada lenguaje químico, y en qué contexto se aplican. Investigadores que han presentado evidencias reveladoras de errores conceptuales en los estudiantes de química - aún en el primer nivel universitario - sostienen que sus dificultades pueden provenir de variadas fuentes como, por ejemplo, de mecanismos mentales de tipo heurísticos (TALANQUER 2006, 2010), o de repeticiones de errores encontrados en el propio discurso experto de docentes y libros de texto. (TABER, 2002).

Proponemos que los lenguajes químicos son las interfases explicitas de la comunicación entre los docentes expertos y los estudiantes novatos. Tal como se muestra en la Figura 1, cabría preguntarse si los estudiantes novatos en un tema podrán fácilmente apropiarse de las significaciones del discurso experto - formulado complementariamente en diversos lenguajes expertos -, considerando que éstas dependen de lo que ya se sabe de un tema (GALAGOVSKY 2004a, 2004b; NOVAK, 1984) y que expertos y novatos se diferencian cabalmente en ese aspecto (de dominio cognitivo del campo de conocimientos específicos). 
Galagovsky, L. R. et al.

Figura 1. Mediación de los lenguajes como interfases de comunicación entre expertos y novatos



Fuente: Elaborado por los autores. 
Más adelante se presentarán dos situaciones que dan cuenta de cómo estudiantes motivados y con buenas calificaciones, pueden aprender solo fragmentos de lenguajes expertos, lo que los conduce a generar respuestas erróneas.

\section{Los estudiantes saben "algo", pero cometen errores...}

Más allá de recursos literarios dentro del lenguaje verbal, como las analogías, metáforas, relatos descriptivos, interpretativos, narrativos, argumentativos, etc., las explicaciones químicas utilizan otros lenguajes expertos (gráfico, matemático, visual, etc.), y cada uno de ellos está formado por "signos" y "sintagmas". Cada signo tiene un aspecto sintáctico explícito observable, denominado "significante" y un aspecto semántico: "el significado" (BOUQUET, 1997; SASSURE, 1964). Una oración química sería el equivalente a un "sintagma" en lingüística. En trabajos previos hemos señalado cómo la abrumadora cantidad de información científica que los estudiantes novatos deben procesar cognitivamente podría causar errores en sus respuestas (sintagmas químicos mal construidos), al reconstruir explicaciones a partir de recuerdos aislados y descontextualizados. (BEKERMAN, 2007, GALAGOVSKY; BEKERMAN, 2009).

Tomando al aula como una situación de intercambio comunicativo entendemos que el docente - o los textos específicos - son el emisor de un mensaje, y cada estudiante es un receptor del mismo y los lenguajes son los canales (SHANNON; WEAVER, 1948). Comprender química significaría que los estudiantes deben decodificar el mensaje entendiendo los significantes y sintagmas; es decir, otorgándoles la misma significación que éstos tienen en la mente del experto que generó el discurso. Desde el marco de la comunicación, el receptor no es un sujeto pasivo mentalmente, en tanto y en cuanto debe decodificar el mensaje y darle una interpretación correcta: similar a la que previó el emisor. Si este proceso comunicativo no se logra se deberá a que el discurso intencional del experto no ha logrado reconstruirse en forma similar en la mente del novato receptor del mensaje.

Para la mayoría de los términos (palabras) que se utilizan en los lenguajes químicos no hay una significación adecuada dentro del lexicón mental de los estudiantes (AITCHISON, 1994), de allí, sus dificultades en insertar tales términos en contextos de significación apropiados. Si extendemos esta situación del lenguaje verbal a los otros lenguajes químicos, podremos dimensionar el anegamiento cognitivo que se le produce al estudiante novato al recibir una inmensa cantidad de información para procesar desde su atención consciente, su memoria de trabajo y su memoria de largo plazo. (BEKERMAN, 2007; GALAGOVSKY; BEKERMAN, 2009). El modo en que cada estudiante contextualice semánticamente los conceptos que debe aprender determinará las relaciones que pueda establecer entre ellos y, estas relaciones condicionarán fuertemente la construcción de su modelo mental (GALAGOVSKY; DI GIACOMO; CASTELO, 2009). Este proceso ocurre para cada uno de los lenguajes componentes del discurso químico.

A continuación presentamos cuatro ejemplos de respuestas erróneas de estudiantes que nos permitirán interpretar - por inducción cualitativa (LIPTON, 1991; MAGNANI, 2001) - posibles orígenes de dificultades para aprender química a partir de su complejo discurso. 
Galagovsky, L. R. et al.

\section{Ejemplo 1}

Un grupo de estudiantes de la asignatura Química (de $4^{\circ}$ año secundaria, 16 años de edad) participaron voluntariamente de una investigación (BEKERMAN, 2007). Luego de la enseñanza tradicional del tema "disoluciones" y de un repaso del mismo (uniones intermoleculares de London, dipolos y enlace ("puente") de hidrógeno), se solicitó a dichos estudiantes - entre otras preguntas - que explicaran mediante dibujos y textos lo ocurrido cuando se disuelve cloruro de sodio en agua (se preparó dicha disolución). Las respuestas gráficas de cuatro estudiantes se muestran en la Figura 2.

Los casos (a) y (b) muestran reinterpretaciones idiosincrásicas sobre la afirmación correcta y frecuentemente esgrimida en las clases de química de disoluciones que expresa en lenguaje verbal "en una disolución el solvente rodea al soluto". Otros elementos correctos son la escritura de " $\mathrm{NaCl}$ " (lenguaje de fórmulas químicas para la sal cloruro de sodio), la idea de agua como "capa de solvente"; hubo en el caso (a) un intento de mostrar una estructura polarizada para el agua, pero incorrectamente dibujada como esferitas conjuntas y alternadas con cargas positivas y negativas. Si bien, entonces, hay elementos aislados correctos -pertenecientes a diferentes lenguajes - su reorganización generó respuestas erróneas. Es decir, signos verbales, íconos y códigos sintácticos gráficos correctos presentes en el discurso de enseñanza fueron guardados desarticuladamente en las memorias de estos estudiantes (GALAGOVSKY; BEKERMAN, 2009). Sería posible inferir, aún, que los estudiantes hubieran construido un modelo parcial sobre cómo se explica la solubilidad de un compuesto en un solvente.

Figura 2. Explicaciones gráficas de cuatro estudiantes sobre la disolución de la sal común (cloruro de sodio, o $\mathrm{NaCl}$ en lenguaje de fórmulas químicas) en agua

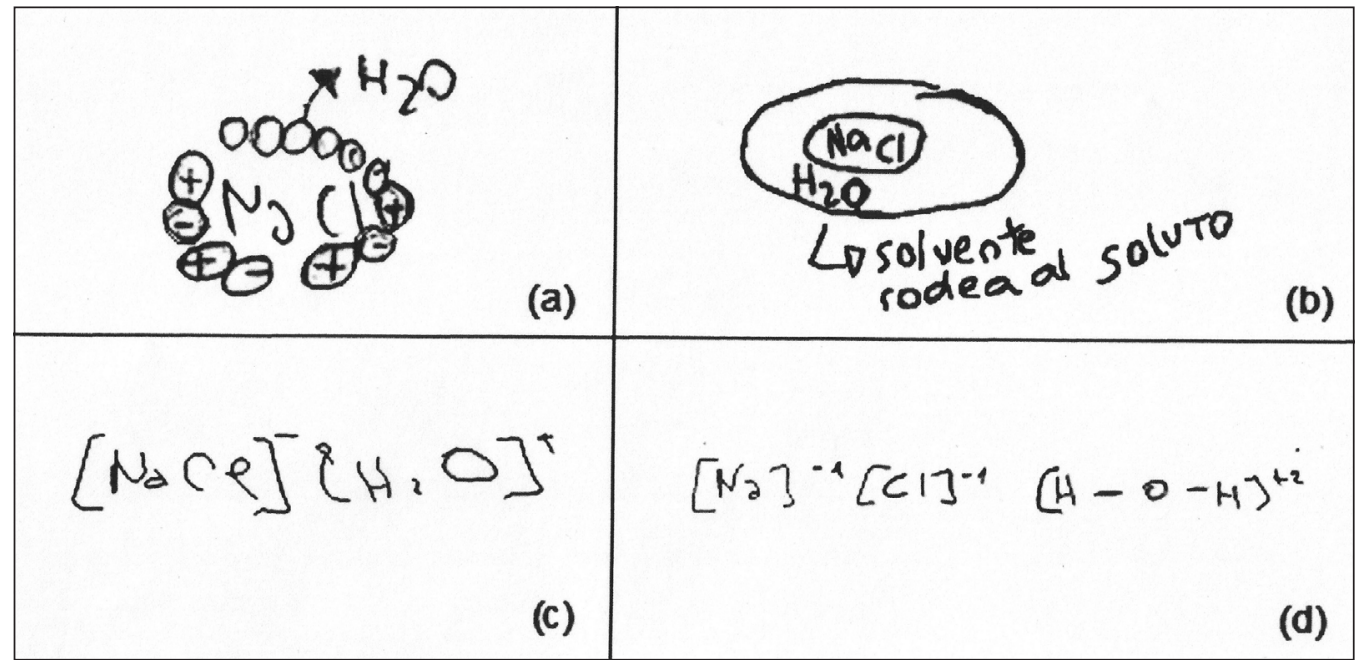

Fuente: Elaborado por los autores. 
En forma similar, en los casos (c) y (d) de la Figura 2 se pueden reconocer íconos del discurso químico, como los corchetes, los signos de carga y las fórmulas de especies químicas, pero utilizados de manera incorrecta, así como la afirmación del discurso químico verbal que expresa que el balance de carga debe ser cero a pesar de la presencia de especies iónicas cargadas. En estos casos no parece posible inferir que los estudiantes hubieran siquiera construido un modelo mental de solubilidad, sino que apelaron al recuerdo descontextualizado de íconos del lenguaje químico gráfico, que reorganizaron en contextos de significación errónea.

Taber (2009) señala que entender química demanda comprender el simbolismo que se utiliza en esta disciplina. Este ejemplo basado en las respuestas erróneas de cuatro estudiantes que han tomado elementos sintácticos explícitos correctos del discurso químico pero que los han reconstruido en sintagmas gráficos idiosincrásicos nos permite ampliar la afirmación de Taber (2009). Identificamos que no cabe aquí considerar la existencia de ideas previas resistentes al cambio conceptual sino la existencia de obstáculos epistemológicos por la dificultad de procesamiento cognitivo de la diversidad de elementos presentes en los diversos lenguajes del discurso experto, donde necesariamente abreva el aprendizaje. (GALAGOVSKY; BEKERMAN, 2009).

\section{Ejemplo 2}

En una experiencia similar a la relatada para la indagación del ejemplo anterior, se solicitó a los estudiantes que explicaran lo ocurrido en una disolución de glucosa en agua, organizando sus respuestas con dibujos y textos. La expectativa era una explicación cualitativa que expresara la acción del solvente agua sobre las moléculas de glucosa, dado su carácter polar por la presencia de grupos hidroxilos. La respuesta de un estudiante y su dibujo correspondiente se muestran en la Figura 3.

En la respuesta puede observarse el esfuerzo memorístico para recordar códigos del lenguaje de fórmulas de la glucosa, necesarios para representar su fórmula cíclica desarrollada, lo cual no era requerido en la consigna. Se observa el uso correcto de guiones para representar

Figura 3. Explicación con dibujo y texto de un estudiante sobre la disolución de azúcar en agua.

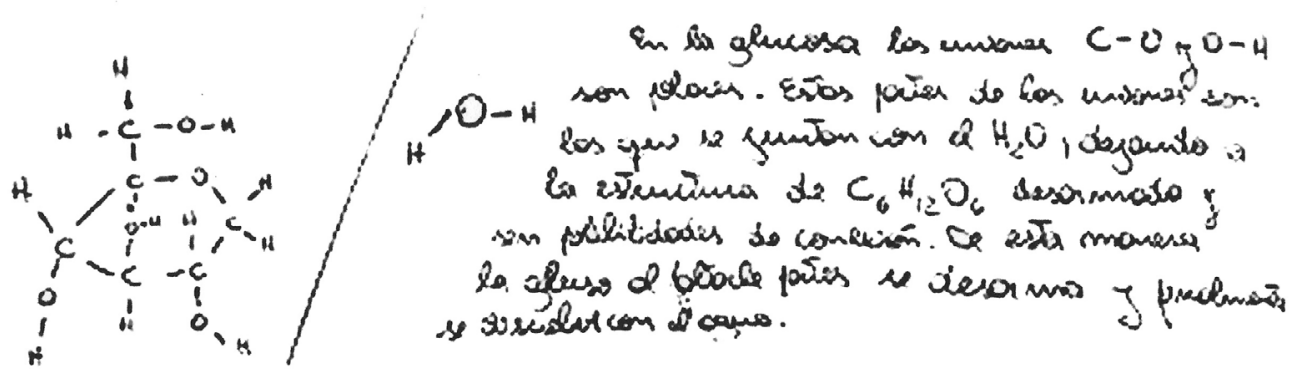

La explicación dice: En la glucosa, las uniones $\mathrm{C}-\mathrm{O}$ y O-H son polares. Estas partes de las uniones son las que se juntan con el $\mathrm{H}_{2} \mathrm{O}$, dejando a la estructura de $\mathrm{C}_{6} \mathrm{H}_{12} \mathrm{O}_{6}$ desarmada y sin posibilidades de conexión. De esta manera la glucosa al faltarle partes se desarma y finalmente se disuelve en el agua.

Fuente: Elaborado por los autores. 
Galagovsky, L. R. et al.

uniones covalentes, la estructura hexagonal de la glucopiranosa, y la fórmula y estructura angular de la molécula de agua.

Respecto de la respuesta verbal se enuncia correctamente que "las uniones C-O y O-H son polares" con lo cual se podría suponer que ya que el agua es un solvente polar podrá interaccionar con la glucosa. Sin embargo, la referencia clara a que la molécula de glucosa "se desarma" y quedan sus partes sin "conexión" es la evidencia de que se ha aplicado el modelo explicativo de disolución de una sustancia iónica al contexto de molécula con enlaces polares.

En este ejemplo, el estudiante parece haber construido un modelo mental sobre la disolución, pero no ha construido ideas correctas acerca de la diferente estabilidad de enlaces iónicos y enlaces covalentes frente a la disolución. Este aspecto debe hacernos reflexionar a los docentes acerca de los riesgos de enseñar exclusivamente con ejemplos paradigmáticos -estereotipados - como recurso didáctico. Es decir, los expertos sabemos que no todo compuesto iónico es soluble en agua; sin embargo este modelo científico complejo que involucra articular tipos de enlace con equilibrio de solubilidad no se enseña en su complejidad a los estudiantes. Por el contrario, la versión didáctica implica generalmente enseñar solubilidad en agua con el modelo de cloruro de sodio como soluto. Este caso es un epitome para el conocimiento experto. (GALAGOVSKY, 2011), pero puede resultar en la construcción cognitiva de un modelo erróneo para el estudiante novato. Nuevamente, es el discurso de enseñanza el que encierra la potencialidad de ser erróneamente comprendido por los estudiantes novatos, mediante generalizaciones heurísticas inapropiadas.

\section{Ejemplo 3}

El siguiente ejemplo es la respuesta de un estudiante de un primer curso universitario de química (Universidad de Buenos Aires) frente a una pregunta de examen incluida en el problema de estequiometría que se muestra en el Cuadro 1 (DI GIACOMO; ALÍ, 2012).

Cuadro 1. Una pregunta sobre el tema estequiometría, tomada en la primera asignatura de química de nivel universitario

Una muestra de $160 \mathrm{~g}$ de cobre (pureza 85,0\%) reacciona con $2.500 \mathrm{~cm} 3$ de disolución de ácido nítrico 4,00 M, con un rendimiento del $90,0 \%$ debido a pérdidas mecánicas, según la ecuación:

$$
\mathrm{Cu}(\mathrm{s})+4 \mathrm{HNO} 3(\mathrm{aq}) \rightarrow \mathrm{Cu}(\mathrm{NO} 3) 2(\mathrm{aq})+2 \mathrm{NO} 2(\mathrm{~g})+2 \mathrm{H} 2 \mathrm{O}(\mathrm{l})
$$

Si la pureza de la muestra de cobre fuera mayor, manteniendo constantes los datos restantes del enunciado, explicar si la masa de $\mathrm{Cu}(\mathrm{NO} 3) 2$ obtenida sería: a) mayor; b) igual; c) menor.

La respuesta del estudiante, sin ningún tipo de cálculo fue:

Si la pureza del cobre aumenta, la masa de reactivo que reacciona es mayor. Por lo tanto, por la Ley de Conservación de la Masa, que dice que la masa de los reactivos es igual a la masa de los productos en una reacción, la masa de productos aumenta al aumentar la masa de los reactivos. 
El análisis de la respuesta permite inferir que el alumno invoca el principio de conservación de la masa y lo aplica a la situación del problema sin considerar cuál es el reactivo limitante.

La generalización inapropiada de la Ley de Conservación de la Masa puede encontrarse también en libros de texto, por ejemplo, en Ferrari et al. (2007, p. 60) dice: “[...] en todos los cambios o reacciones químicas la cantidad de materia inicial (la de los reactantes) es igual a la final (la de los productos), en otras palabras, permanece constante." Enunciado de esta manera se supone que la cantidad de materia final es la de los productos. Sin embargo, en el sistema final, podría haber también una cierta masa de algún reactivo en exceso o aun de todos los reactivos si el estado final es de equilibrio químico. La pregunta que debemos hacernos los docentes es ¿qué queremos significar con el término "productos"? Los docentes debemos reflexionar sobre cómo discriminar la terminología en forma oportuna.

Este ejemplo da cuenta de cómo el discurso experto restringido para resultar útil en una situación particular como la del balanceo de una ecuación química, puede provocar generalizaciones incorrectas. El experto puede comprender las diferencias entre los términos "producto" y "sistema final", los estudiantes, en cambio, podrían analogar dichos términos. En este caso estarían aplicando la Ley de Conservación de la Masa sin tener en cuenta, ni la presencia de impurezas, ni la de reactivos en exceso que queden sin reaccionar, como tampoco los casos de reacciones reversibles, en los cuales el sistema final está constituido también por reactivos.

Nuevamente, la simplificación de modelos expertos en el discurso químico de enseñanza conduce a los estudiantes novatos a "hablar química" de una manera aparentemente correcta, pero que en forma subyacente encripta la construcción de conocimientos inadecuados desde el punto de vista científico.

\section{Ejemplo 4}

En el contexto de un taller sobre fuerzas intermoleculares se planteó a los participantes realizar individualmente la experiencia macroscópica de mezclar en tres respectivos tubos de ensayo volúmenes iguales de agua con (a) alcohol (etanol), (b) con aceite de cocina, y (c) con alcohol más aceite; luego se debía agitar cada tubo y dejarlo reposar para, finalmente, explicar los fenómenos ocurridos tanto a nivel macroscópico como a nivel particulado, utilizando lenguaje verbal y dibujos. Un estudiante participante, que estaba promediando su Profesorado Universitario en Física (3er año, Universidad de Buenos Aires) señaló en sus explicaciones que "el experimento de agua más alcohol habia fallado, pues esperaba encontrar dos fases y se habia formado una sola".

Sus dibujos de nivel microscópico mostraban símbolos de partículas esféricas para señalar a una fase de alcohol en la parte superior de un tubo de ensayo, y otro código para señalar a las partículas del agua en la parte inferior del mismo tubo. Su argumento verbal fue que "el alcohol es menos denso que el agua y por ello se ubica en la parte superior del tubo de ensayo". Su expectativa era que como la densidad del alcohol es menor que la del agua, al igual que en el caso de aceite-agua, se formaran dos fases. Para el tercer tubo con la mezcla de los tres solventes el estudiante había encontrado aplicable su argumento, ya que "cada sustancia tiene diferente densidad y, por lo tanto, debian observarse tres fases" - en realidad, el aspecto del tubo evidenciaba la presencia de dos fases turbias y una interfase de emulsión (GALAGOVSKY; DI GIACOMO; CASTELO, 2009).

La propuesta docente esperaba poner en conflicto anticipaciones de los estudiantes respecto de qué podría pasar y la aceptación de que cualquier modelo explicativo a nivel sub- 
microscópico debería recurrir a la existencia de entidades tales como fuerzas de atracción - o no - entre las partículas de los diferentes solventes. En este ejemplo resulta evidente que el concepto de densidad era el marco teórico único a través del cual este estudiante de Física pudo generar una respuesta. El modelo de densidad resultaba en él tan fuertemente arraigado que lo hizo aún dudar del resultado observable de la experiencia macroscópica.

Es decir, este ejemplo revela que los modelos mentales aprendidos son marcos interpretativos poderosos y que no resulta sencillo ponerlos en cuestionamiento, aún desde una evidencia experimental indiscutible. Este punto acercaría posiciones con los trabajos de investigación educativa que presentan a las ideas erróneas de los estudiantes como teorías implícitas, y a proponer que un necesario cambio conceptual debe pasar por tomar conciencia sobre esa idea previa. Nuevamente, no se trata de una idea previa construida desde la vida cotidiana; por el contrario, el hecho cotidiano sería haberse dado cuenta de que alcohol común y agua forman un sistema homogéneo. Es decir, la idea resistente provenía de sus aprendizajes escolares previos; en este caso, del modelo explicativo de densidad para la flotación de los cuerpos como suficiente para explicar cualquier situación de mezclas.

Los docentes debemos reflexionar sobre alcances y limitaciones de los modelos científicos que presentamos, para alcanzar más el "comprender ciencia" que el sólo "hablar ciencia". Por ejemplo: el agua por definición tiene una densidad de $1 \mathrm{~kg} / \mathrm{dm}^{3}$; la brea tiene una densidad aproximada de $1,8 \mathrm{~kg} / \mathrm{dm}^{3}$, la acetona de $0,79 \mathrm{~kg} / \mathrm{dm}^{3}$, y el ácido sulfúrico de $1,84 \mathrm{~kg} / \mathrm{dm}^{3}$; estos datos no sirven para predecir la solubilidad entre pares de estos compuestos. Los docentes cuidadosamente separamos los ejemplos y ejercicios donde sí se pueden aplicar modelos de flotabilidad relativa según la densidad, de disolución según el tipo de enlace químico y de descripción de fuerzas intermoleculares; también presentamos a los estudiantes numerosos ejercicios con cálculos en los cuales la densidad es un dato necesario; sin embargo, la relación entre densidad y fuerzas intermoleculares no se analiza en la escuela secundaria. Esta relación sí permitiría interpretar infinidad de situaciones y fenómenos de la vida cotidiana.

\section{Reflexiones finales}

Las conclusiones principales de este trabajo han permitido la construcción de la red conceptual de la Figura 4 (GALAGOVSKY, 1999) donde se diferencian a expertos y novatos, sus respectivos modelos mentales y sus relaciones con la información explícita que constituye el discurso de enseñanza, para, finalmente, mostrar el sustento epistemológico diferente entre "hablar ciencia" y "comprender ciencia".

Dos reflexiones principales se plantean a continuación.

\section{Desde el enfoque de la investigación en educación química}

El presente trabajo no pretende ser una colección de respuestas de estudiantes categorizadas en función de sus coherencias y consistencias como ideas previas, esquemas conceptuales alternativos, o desde sus resistencias al cambio conceptual a pesar de la instrucción (OLIVA MARTÍNEZ, 1999), o de asignar a los estudiantes metodologías superficiales o inferencias y generalizaciones acríticas (FINEGOLD; GORSKY, 1991; GIL; CARRASCOSA, 1990; HEW- 
SON, 1990; OLIVA MARTÍNEZ, 1996; VIENNOT, 1985). Estos tipos de trabajos - muy abundantes en la literatura en didáctica de las ciencias - han pretendido encontrar regularidades en las respuestas erróneas de los estudiantes, o detectar esquemas alternativos de pensamiento propios de mentes no expertas en temas científicos; o, incluso, encontrar heurísticos frecuentes en estudiantes, conducentes a respuestas erróneas (TALANQUER, 2006, 2010). El aporte innovador del presente trabajo es que permite reconocer que dentro del propio discurso docente de química puede encontrarse parte importante del origen de los errores en los estudiantes novatos de química, debido a recortes y estereotipos provenientes de decisiones didácticas, así como de las dificultades inherentes al procesamiento de información proveniente de sus complejos lenguajes.

Desde nuestro punto de vista aceptamos que el conocimiento que maneja un experto requiere la mediación del lenguaje para ser comunicado. Por otra parte, el estado de conocimiento adquirido por cada estudiante sólo podrá evaluarse si éste lo hace explícito. Los discursos explícitos, por lo tanto, son fuentes de comunicación, y también pueden ser origen de errores cuando los estudiantes novatos en el tema se ven forzados a utilizarlos, habiendo sido sus aprendizajes fundamentalmente de tipo memorístico. Aceptar que la complejidad del discurso de química es fuente de potencial incomunicación entre docentes y estudiantes, significa aceptar que algunas fallas en el aprendizaje de los estudiantes no serían simplemente el resultado de sus escasas dedicaciones al estudio. Esta aceptación conlleva a admitir que un estudiante puede hacer esfuerzos por aprender el discurso químico, pero que si ese discurso le tiende trampas por la complejidad de sus lenguajes, o por recortes estereotipados en sus modelos producto de decisiones didácticas supuestamente beneficiosas, entonces, él tendrá grandes chances de cometer errores de aprendizaje, de comprensión. Ese estudiante se desmotivará frente a la asignatura, pues, además de equivocarse al "hablar ciencia", posiblemente lo que más lo entristezca sea la futilidad de todo esfuerzo en "comprender ciencia".

Las cuestiones fundamentales planteadas en este trabajo constituyen reflexiones desde el enfoque de la comunicación (LITTLEJOHN; FOSS, 2008; SHANNON; WEAVER, 1949), aplicadas al contexto de la clase de ciencias. Desde este encuadre, consideramos al discurso de enseñanza científica como el mensaje, a los estudiantes como receptores del mensaje, al aprendizaje como el resultado de la decodificación del mensaje con una significación adecuada ("comprender ciencia"), y a la habilidad de "hablar ciencia" como una manifestación de correcta utilización de la sintaxis de los lenguajes científicos.

\section{Desde el enfoque de la enseñanza de la química}

La elección de temas, modelos a enseñar y estrategias didácticas a utilizar es responsabilidad de los docentes (MONEREO FONT, 2010; VIENNOT, 2006). Los estudiantes novatos reciben pasivamente una cantidad abrumadora de información científica escolar; ellos tratan de comprender y quizás lo logran en pequeñas tramas de significaciones, debiendo fundamentalmente memorizar fragmentos de lenguajes pertenecientes a discursos descontextualizados.

Generalizaciones indebidas, aplicación de estructuras parcializadas de comprensión a otros contextos y/o reinterpretaciones en modelos mentales idiosincrásicos son las consecuencias evidentes que surgen en la investigación y no necesariamente se detectan en las evaluaciones tradicionales. 
Galagovsky, L. R. et al.

Figura 4. Diferencias entre "hablar ciencia" y "comprender ciencia". La función de los modelos para expertos y novatos



Fuente: Elaborado por los autores. 
La dificultad de presentar discursos complejos y amplios conduce a reducciones y simplificaciones que forman parte de trasposiciones didácticas genuinamente planteadas por el docente experto, pero que pueden conducir a graves errores de conceptualización y modelización en los estudiantes. Más allá de situaciones de investigación, donde estos hechos se ponen en evidencia, los estudiantes cumplen su oficio de alumno, de la mejor forma posible, generalmente estudiando y respondiendo con gran esfuerzo memorístico y poca motivación.

Lo expuesto en este trabajo imprime un factor más de presión para reflexionar sobre qué decisiones curriculares tomar con miras a la enseñanza en el siglo XXI, partiendo del ya sobredimensionado currículo de química de escuela secundaria. Finalmente, autores como Ausubel, Novak y Hanesian (1983) han señalado que un mejor conocimiento acerca de cómo aprenden los estudiantes y la influencia de variables de cambio en los procesos de aprendizaje podrín repercutir directamente en la búsqueda de fórmulas tendientes a ayudarles a aprender mejor.

\section{Referencias}

AITCHISON, J. Words in the mind: an introduction to the mental lexicon. Oxford: Blackwell, 1994.

AUSUBEL, D. P.; NOVAK, J. D.; HANESIAN, H. Psicología educativa: un punto de vista cognitivo. México: Trillas, 1983.

BARKER, V. Beyond appearances: students' misconceptions about basic chemical ideas: a report prepared for the Royal Society of Chemistry. London: Royal Society of Chemistry, 2000.

BEKERMAN, D. G. La utilización de la imagen en los procesos de enseñanza y aprendizaje de química orgánica. 2007. 249 h. Tesis (Doctoral) - Facultad de Farmacia y Bioquímica, Universidad de Buenos Aires, Buenos Aires, 2007.

BEN-ZVI, N.; GAI, R. Macro and micro-chemical comprehension of real-world phenomena: classroom knowledge versus the experience of the senses. Journal of Chemical Education, Easton, v. 71, n. 9, p. 730-734, 1994.

BOUQUET, S. Introduction à la lecture de Saussure. Paris: Payot \& Rivages, 1997.

CARMICHAEL, P. et al. Research on students' conceptions in science: a bibliography. [Leeds]: University of Leeds: Centre for Studies in Science and Mathematics Education, 1990.

CARR, M. Model confusion in chemistry. Research in Science Education, Dordrecht, v. 14, n. 1, p. $97-103,1984$.

DE VOS, W.; BULTE, A. M. W.; PILOT, A. Chemistry curricula for general education: analysis and elements of a design. In: GILBERT, J. K. et al. (Ed.). Chemical education: towards a research-based practice. Dordrecht: Kluwer, 2003. p. 101-124.

DI GIACOMO, M. A.; ALÍ, S. Reacciones químicas: dificultades en su aprendizaje. In: JORNADAS DE INGRESO Y PERMANENCIA EN CARRERAS CIENTÍFICO-TECNOLÓGICAS, 3., 2012, San Juan. Actas... San Juan: Universidad Nacional de San Juan, 2012.

FERRARI, A. et al. Física y química: naturaleza corpuscular y carácter eléctrico de la materia. Magnetismo. Fuerzas. Buenos Aires: Santillana, 2007. 
Galagovsky, L. R. et al.

FINEGOLD, M.; GORSKY, P. Students' concept of force as applied to related physical systems: a search for consistency. International Journal of Science Education, London, v. 13, n. 1, p. 97-113, 1991.

GALAGOVSKY, L. Del aprendizaje significativo al aprendizaje sustentable. Parte I: el modelo teórico. Enseñanza de las Ciencias, Barcelona, v. 22, n. 2, p. 229-240, 2004a.

Del aprendizaje significativo al aprendizaje sustentable. Parte II: implicancias comunicacionales y didácticas. Enseñanza de las Ciencias, Barcelona, v. 22, n. 3, p. 349-363, 2004b.

GALAGOVSKY, L. (Coord.). Didáctica de las ciencias naturales: el caso de los modelos científicos. Buenos Aires: Lugar Editorial, 2011.

GALAGOVSKY, L. Enseñanza de las ciencias naturales: un desafío a nivel mundial. El caso particular de enseñanza de la química. Revista Proyecciones, Buenos Aires, v. 6, n. 2, p. 23-36, 2008.

Redes conceptuales: memoria, comunicación y aprendizaje. Buenos Aires: Lugar Editorial, 1999.

GALAGOVSKY, L.; BEKERMAN D. La química y sus lenguajes: un aporte para interpretar errores de los estudiantes. Revista Electrónica de Enseñanza de las Ciencias, Vigo, v. 8, n. 3, p. $952-$ 975, 2009. Disponible en: <http://www.saum.uvigo.es/reec/volumenes/volumen8/ART11_Vol8_ N3.pdf>. Acceso el: 11 ago. 2014.

GALAGOVSKY, L.; DI GIACOMO, M. A.; CASTELO, V. Modelos vs. dibujos: el caso de la enseñanza de fuerzas intermoleculares. Revista Electrónica de Enseñanza de las Ciencias, Vigo, v. 8, n. 1, p. 1-22, 2009. Disponible en: <http://www.saum.uvigo.es/reec/volumenes/volumen8/ ART1_Vol8_N1.pdf>. Acceso el: 11 ago. 2014.

GIL, G; CARRASCOSA, J. What to do with science "misconceptions". Science Education, Hoboken, v. 74, n. 5, p. 531-540, 1990.

GILBERT, D.; TREAGUST, D. F. (Ed.). Multiple representations in chemical education. Dordrecht: Springer, 2009.

GROSSLIGHT, L. et al. Understanding models and their use in science: conceptions of middle and high school students and experts. Journal of Research in Science Teaching, East Lansing, v. 28, n. 9, p. 799-822, 1991.

HARRISON, A. G.; TREAGUST, D. F. Learning about atoms, molecules, and chemical bonds: a case study of multiple-model use in grade 11 chemistry. Science Education, Hoboken, v. 84, n. 3, p. 352-381, 2000.

HEWSON, P. La enseñanza de "fuerza y movimiento" como cambio conceptual. Enseñanza de las Ciencias, Barcelona, v. 8. n. 2, p. 157-171, 1990.

JOHNSTONE, A. H. Teaching of chemistry: logical or psychological? Chemical Education: research and practice in Europe, Ioannina, v. 1, n. 1, p. 9-15, 2000.

Why is science difficult to learn?: things are seldom what they seem. Journal of Computer Assisted Learning, Malden, v. 7, n. 2, p. 75-83, 1991.

. You cant't get there from here. Journal of Chemical Education, Easton, v. 87, n. 1, p. 22-29, 2010.

LEMKE, J. L. Aprender a hablar ciencia: lenguaje, aprendizaje y valores. Barcelona: Paidós Ibérica, 1997. 
LIPTON, P. Inference to the best explanation. London: Routledge, 1991.

LITTLEJOHN, S. W.; FOSS, K. A. Theories of human communication. 9th. ed. Belmont: Thomson Wadsworth, 2008.

MAGNANI, L. Abduction, reason, and science. Dordrecht: Kluwer; New York: Plenum, 2001.

MONEREO FONT, C. ¡Saquen el libro de texto!: resistencia, obstáculos y alternativas en la formación de los docentes para el cambio educativo. Revista de Educación, Madrid, v. 352, p. 583-597, 2010.

NOVAK, J. Teoría y práctica de la educación. Madrid: Alianza, 1984.

OLIVA MARTÍNEZ. J. M. Algunas reflexiones sobre las concepciones alternativas y el cambio conceptual. Enseñanza de las Ciencias, Barcelona, v. 14, n. 1, p. 87-92, 1999.

. Estudios sobre consistencia en las ideas de los alumnos en ciencias. Enseñanza de las Ciencias, Barcelona, v. 17, n. 1, p. 93-107, 1996.

SAUSSURE, F. Course in general linguistics. London: Peter Owen, 1964.

SHANNON, C. E.; WEAVER, W. A mathematical theory of communication. Urbana: University of Illinois Press, 1948.

TABER, K. S. Building the structural concepts of chemistry: some considerations from educational research. Chemistry Education: research and practice in Europe, Ioannina, v. 2, n. 2, p. 123-158, 2001.

. Chemical misconceptions: prevention, diagnosis and cure. London: Royal Society of Chemistry, 2002. v. 1.

. Learning at the symbolic level. In: GILBERT, J. K.; TREAGUST, D. (Ed.). Multiple representations in chemical education. Dordrecht: Springer, 2009. p. 75-105.

TALANQUER, V. Commonsense chemistry: a model for understanding students' alternative conceptions. Journal of Chemical Education, Easton, v. 83, n. 5, p. 811-816, 2006.

TALANQUER, V. Pensamiento intuitivo en química: suposiciones implícitas y reglas heurísticas.

Enseñanza de las Ciencias, Barcelona, v. 28, n. 2, p. 165-174, 2010.

VIENNOT, L. Analysing students' reasoning in science: a pragmatic view of theoretical problems.

European Journal of Science Education, London, v. 7, n. 2, p. 151-162, 1985.

. Teaching rituals and students intellectual satisfaction. Physics Education, London, v. 41, n. 5, p. 400-408, 2006. 